\title{
PLANO DE GERENCIAMENTO INTEGRADO DE RESÍDUOS SÓLIDOS EM UM RESTAURANTE INSTITUCIONAL: UMA FERRAMENTA OPERACIONAL, VISANDO MELHORIAS NA GESTÃO AMBIENTAL
}

\author{
PLAN FOR INTEGRATE MANAGEMENT OF SOLID \\ RESIDUES IN THE INSTITUTIONAL RESTAURANT: \\ OPERATIONAL TOOL TARGETING IMPROVEMENTS \\ IN ENVIRONMENTAL MANAGEMENT
}

\section{Claudia Leite Carneiro}

Universidade Federal do Rio Grande do Norte, UFRN. Avenida Senador Salgado Filho, 3000 - Lagoa Nova, Natal - RN, 59078-970. E-mail:

claudialeite@supercabo.com.br

\begin{abstract}
RESUMO
A preocupação com a conservação do meio ambiente atinge diferentes camadas e setores da sociedade mundial. Assim, visando analisar uma ferramenta operacional para melhoria na gestão ambiental de um restaurante institucional, foi aplicado um plano de gerenciamento integrado de resíduos sólidos. Os resíduos produzidos foram caracterizados, classificados de acordo com sua natureza, em resíduo seco ou úmido, ajustados de acordo com normas específicas dos Serviços de Alimentação e Nutrição. Como resultado da aplicação do plano, observou-se um expressivo volume de resíduos gerados, refletindo uma cultura de desperdício, que agride o meio ambiente e implica em aumento de custos e gastos da Unidade. O Plano de Gerenciamento Integrado de Resíduos enfatiza a importância da promoção de ações que permitam a aplicação desta ferramenta para alcance de efeitos positivos na instituição nas áreas econômica e ambiental.
\end{abstract}

Palavras-chave: Unidade de Alimentação e Nutrição. Meio Ambiente. Gestão ambiental. Gerenciamento de Resíduos Sólidos.

\footnotetext{
ABSTRACT

Globally, the concern for environmental conservation reaches different layers and sectors of the society. Thus, aiming to analyze operational tool improvements in environmental management from an institutional restaurant, applied a plan for integrated management of solid waste. The produced waste was characterized and classified according to its nature as dry or wet residues, and adjusted according to specific standards of Food and Nutrition Services. The results showed a significant volume of waste generated, pointing to a wasteful culture, which harms the environment and increases the costs and expenses of the Unit. Emphasizing the importance of promoting actions, those enable the application of this tool for achieving positive effects on institutions in the economic and environmental areas.

Keywords: Food and Nutrition Unit. Environment. Environmental management. Solid Waste Management.
} 


\section{INTRODUÇÃO}

Muito se tem falado sobre a implantação do Gerenciamento de Resíduos Sólidos, entretanto, escassos são os artigos nos quais se analisa um sistema integrado que considere e avalie todas as etapas necessárias para a maximização da utilização dos recursos disponíveis. O gerenciamento integrado de resíduos sólidos (GIRS) é definido atualmente pela legislação que instituiu a Política Nacional de Resíduos Sólidos, na Lei 12.305/2010, como um "conjunto de ações exercidas direta ou indiretamente, nas etapas de coleta, transporte, transbordo, tratamento e destinação final ambientalmente adequada dos resíduos gerados e dos rejeitos, de acordo com o plano municipal de gestão integrada de resíduos sólidos ou com plano de gerenciamento exigido nesta Lei" (BRASIL, 2010).

Um programa integrado fundamentado na maximização dos recursos disponíveis ao homem deve envolver etapas como descritas na definição da Lei e ordenadas com a identificação dos resíduos. Para os autores que atuam na área, a coleta, tratamento e disposição inadequada de resíduos sólidos têm fortes impactos sociais e econômicos. Muitos desses impactos negativos são de amplo conhecimento, entretanto, a questão dos resíduos tem sido, por muitas vezes, negligenciada, produzindo situações potencialmente destrutivas e refletindo esses danos sobre gerações futuras (MENEZES e MENEZES, 1999).

Nos sistemas produtivos geradores de resíduos, destacam-se as Unidades de Alimentação e Nutrição (UANs), que, além da produção de refeições com qualidade, deveriam também fazer uso de práticas e processos de trabalho ambientalmente corretos. A geração de resíduos em toda a cadeia produtiva nas UANs é parte da realidade operacional produtiva brasileira, partindo desde o recebimento dos gêneros que comporão a refeição até sua distribuição final. Controlar a geração desses resíduos, com objetivo de conservar o meio ambiente, é fundamental para que haja interação das ferramentas de implantação do plano de gerenciamento de resíduos com as rotinas de produção de uma UAN. Partindo de um diagnóstico ambiental, pode-se realizar revisão dos processos produtivos nas UANs, estabelecendo-se objetivos ambientais, adequando organogramas, fluxogramas e, assim, redigindo um plano de gerenciamento de resíduos, estabelecendo sistemas de controle das operações, de gestões e de registros nessas referidas unidades.

Os planos de gerenciamentos de resíduos sólidos se inserem nesta problemática como uma ferramenta equalizadora da gestão ambiental, permitindo tomada de decisão frente a resíduos gerados. Esses planos deverão ser elaborados por técnicos habilitados e conter informações primordiais do estabelecimento e ou empreendimentos envolvidos (MENEZES E MENEZES, 1999). O modelo de referência proposto por esses autores tem sua conformação bastante similar ao Manual de Boas Práticas de Fabricação, proposto pela Resolução RDC nº 216/2004 (BRASIL, 2004), tornando-o extremante conveniente, de fácil replicação, exequível e oportuno na elaboração de um plano de gerenciamento integrado de resíduos sólidos em restaurantes.

Dentre essas ferramentas, observa-se a identificação dos resíduos que tem por finalidade garantir o conhecimento dos produtos gerados e subsídios para a segregação nos locais de geração, fornecendo dados para conhecimento da realidade e delineando ações normativas, operacionais, financeiras e de planejamento que envolvam a questão do processamento articulado das ações necessárias para minimização da geração dos resíduos e operações posteriores para reduções dos mesmos (MONTEIRO et al., 2001).

Partindo desta realidade, infere-se que a conservação ambiental é uma questão a ser enfrentada e defendida, e, assim sendo, os sistemas de produção, sejam estes de amplitude a quaisquer finalidades propostas, necessitam conscientizar-se que, no decorrer de seus processos produtivos, se houver uma condução irresponsável, esta postura agredirá cada vez mais o meio ambiente. O Plano de Gerenciamento de Resíduos Sólidos atua como ferramenta equalizadora destes riscos. 


\section{MATERIAL E MÉTODOS}

Como método de pesquisa, utilizou-se a ferramenta metodológica a pesquisa-ação e o local para a análise das etapas do sistema de produção foi um Restaurante Universitário (RU) localizado na Universidade Federal do Rio Grande do Norte, Campus Natal, órgão meio e sem fins lucrativos.

$\mathrm{O}$ atendimento do restaurante no período da coleta compreendeu 2260 refeições/dia, sendo dispostas em 160 desjejuns, 1600 almoços e 500 jantares, em média. O restaurante funciona também nos finais de semana, para atender a comunidade acadêmica residente na instituição. O estudo foi realizado durante a época letiva, o que dá pico de uso nas instalações. Em períodos de férias, o número de comensais é reduzido, bem como nos finais de semana, uma vez que o calendário acadêmico desenvolve suas atividades em maior volume de segunda a sexta, e com isto há diminuição da geração do resíduo e do per capita do resíduo gerado.

A análise observacional identificou grande número de resíduos gerados no RU, e assim levantaram-se dados e postulados entendimentos sobre o processo produtivo de resíduos gerados. Buscou-se, inicialmente, a interação cooperativa entre a pesquisa e os participantes atuantes na situação observada (funcionários, estagiários e chefia do RU).

Com a finalidade de coletar apontamentos sobre visões dos resíduos gerados no local, foram realizadas reuniões com estagiários, funcionários e chefia, discutindo-se o tema e formulando a apresentação do projeto. Objetivos foram definidos com a intenção de traçar metas para sua execução e definir, posteriormente, a esfera de aplicação de um plano de Gerenciamento de Resíduos Sólidos no RU e possíveis propostas referentes à educação ambiental.

Foi aplicado um questionário com perguntas objetivas aos funcionários e à chefia, levantando questões sobre perfil pessoal, percepção do resíduo gerado e vias de como minimizar e melhorar a produção dos resíduos. Para levantamento relacionado à educação ambiental de funcionários, gestores, estagiários e supervisores, foi realizada uma pesquisa com demanda espontânea entre os funcionários.

A coleta de dados foi realizada em quatro semanas consecutivas, incluindo fins de semana e cardápios diferentes, no mês de setembro de 2009. A amostragem diária foi coletada visando pesagem de todos os resíduos gerados por dia no período da coleta e os registros foram anotados em planilha simples, contendo informações sobre a data, tipo de resíduo gerado, peso e local de origem. Depois, foram somados os quantitativos das amostras diárias durante 21 dias úteis e 10 dias em fins de semana.

Por tratar-se de uma unidade de alimentação e para fins de análise dos processos produtivos, foram utilizados instrumentos da nutrição como o fator de correção, a análise do rejeito, a satisfação subjetiva do cliente e o desperdício de estoque. $\mathrm{O}$ fator de correção corresponde à perda em relação ao peso inicial representada pelas partes não comestíveis dos alimentos e é representado pela relação do peso bruto e o peso líquido do alimento. A análise do rejeito foi avaliada pela equação, segundo Abreu et al. (2007):

Índice de Resto (IR) = Peso da Refeição Rejeitada (PR) x 100/Peso

A pesquisa de satisfação subjetiva do cliente buscou identificar os itens que permitissem conhecer as causas do problema na execução organoléptica do cardápio. Ela foi levantada, partindo de questionário de perguntas objetivas e subjetivas, contendo opções de classificação do cardápio como bom, regular e ruim, bem como espaço para que o cliente expressasse suas impressões sobre o cardápio. E, a partir deste ponto, fornecer dados, em uma segunda etapa, para o diagnóstico sobre modos de preparo, sabores e apresentações das preparações no cardápio de dia. 
Essa coleta da análise subjetiva do cliente foi executada em cinco dias consecutivos na implantação de um cardápio. E o desperdício de estoque foi analisado partindo de anotações diárias de alimentos desprezados do almoxarifado ou sobras descartadas por quaisquer razões produtivas (sobras inviáveis de reuso, grau de amadurecimento elevado de alimentos, entre outros).

Quanto à caracterização dos resíduos produzidos, esta etapa foi realizada a partir de um levantamento do quantitativo e qualitativo do lixo total do local, para obter o percentual de resíduo úmido e resíduo seco gerado. Em sequência, foi calculada a média diária de produção do resíduo úmido e seco, separadamente, por semana (segunda a sexta), fim de semana (sábado e domingo) e por mês, para obter melhor visualização do quantitativo produzido de cada tipo de resíduo e comparar a diferença dos resultados dos fins de semana e das semanas, com relação à média mensal.

O método escolhido, de acordo com a disposição de sua natureza (secos e úmidos) foi segundo classificação da NBR ISO 14004 (ASSOCIAÇÃO BRASILEIRA DE NORMAS TÉCNICAS, 1996): Sistemas de gestão ambiental com diretrizes gerais sobre princípios, sistemas e técnicas de apoio, adaptada por Kinasz (2007) que ajusta as normas à realidade específica dos serviços de alimentação e nutrição, como descritos abaixo:

- PAPEL/PAPELÃO: caixas de papelão, sacos e sacolas de papel, outros tipos de invólucros de papel ou papelão, toalhas e guardanapos de papel;

- VIDROS: vidros de acondicionamento de alimentos e de produtos de higiene;

- LATAS: latas de acondicionamento de alimentos de produtos de higiene e desinfecção;

- APARAS E RESÍDUOS DE PRÉ-PREPARO E PREPARO DE ALIMENTOS: partes retiradas dos alimentos como cascas, sementes, talos, folhas danificadas, raízes, peles, cartilagens, ossos, entre outras, nas atividades denominadas de pré-preparo (fase que envolve a lavagem, limpeza, corte e temperos dos alimentos a serem preparados).Preparo dos alimentos e restos de alimentos contidos nos utensílios.

- RESTOS/SOBRAS: restos das preparações que compõem o cardápio e que são deixados pelo cliente na bandeja/prato. As sobras são: preparações não consumidas pelos clientes e que não são passíveis de reutilização.

Para a proposição de um Plano de Gerenciamento de Resíduos Sólidos no Restaurante Universitário da UFRN, foram utilizados parâmetros definidos em subsídios legais, considerando a Lei $\mathrm{n}^{\circ}$ 12.305/2010 (BRASIL, 2010) que instituiu a Política Nacional de Resíduos Sólidos, diretrizes e especificações. Partindo do ajuste desta normativa, em conformidade com as legislações utilizadas no âmbito da Nutrição, foram utilizadas as Resoluções RDC no 216/2004 (BRASIL, 2004) que dispõem sobre o Regulamento Técnico de Boas Práticas para Serviços de Alimentação e a RDC n 275/2002 (BRASIL, 2002), que dispõem sobre o regulamento técnico de procedimentos operacionais padronizados, aplicados aos estabelecimentos produtores/industrializadores de alimentos e a lista de verificação das boas práticas de fabricação em estabelecimentos produtores/ industrializadores de alimentos.

O modelo escolhido para a elaboração do Plano de Gerenciamento foi baseado naquele proposto por Menezes e Menezes (1999), tendo como critério seletivo a característica de ser organizacional e didaticamente similar ao organizacional do Manual de Boas Práticas de Fabricação (MBPF), instrumento utilizado obrigatoriamente na Nutrição. Este é aplicado e conhecido nas UANs, o que facilitará a elaboração e implantação de Plano de Gerenciamento Integrado de Resíduos em UANs. Na descrição, o plano consistia de três etapas bem definidas: etapa 1 identificação do gerador; etapa 2 - diagnóstico atual; etapa 3 - descrição do plano de gerenciamento.

$\mathrm{Na}$ aplicação do Plano neste estudo, na etapa I de identificação do gerador serão obtidas informações gerais quanto à tipologia do empreendimento: descrição da atividade, fluxograma e os procedimentos realizados no empreendimento; será diagnosticada à UAN quanto à subordinação à 
Pró Reitoria de Assuntos Estudantis e à Reitoria, sendo os recursos destinados ao financiamento desta procedentes do Governo Federal.

Na etapa 2 do Plano, que compreenderá a elaboração do diagnóstico da situação atual e dos resíduos gerados, serão identificados dados que permitam a reavaliação dos sistemas produtivos e operacionais que são demandados para confluir em ajustes globais nas unidades de alimentação moldados pela sustentabilidade.

$\mathrm{Na}$ etapa 3, ocorrerá a descrição do plano de gerenciamento. Para metas de educação ambiental será descrito programa de conscientização e treinamento para os funcionários da empresa terceirizada, dos funcionários federais, clientes, fornecedores e chefias. E ainda relacionadas as metas para a redução de geração, bem como os resíduos destinados à reutilização e à reciclagem, especificando classificação e quantidade.

Quanto à destinação dos resíduos passíveis de reutilização ou reciclagem, foram fornecidos nomes das empresas geradoras e das conveniadas para reciclagem, com endereços, telefones/fax e dados dos responsáveis técnicos, assim como os procedimentos de manejo utilizados na segregação dos resíduos.

O acondicionamento por tipo ou grupo de resíduos e os tipos de recipientes utilizados para esse fim foram descritos conforme a capacidade e estabelecidos procedimentos para o correto fechamento, vedação e manuseio dos recipientes, de forma a evitar vazamentos e/ou ruptura dos mesmos e inseridos símbolos de identificação compatíveis com o tipos de resíduos acondicionados.

Para a coleta e transporte interno dos resíduos, foram descritos os procedimentos das medidas a serem adotadas em caso de rompimento de recipientes, vazamento de líquidos, derrame de resíduos, ou ocorrência de outras situações indesejáveis, bem como a forma de higienização dos recipientes e equipamentos e os produtos empregados, apresentando planta baixa do estabelecimento e especificação das rotas dos resíduos. Ainda foram descritos: a área de armazenamento temporário, obedecendo às medidas de segurança e proteção ambiental de impermeabilização do piso; cobertura e ventilação; isolamento e sinalização; acondicionamento adequado; controle de operação; treinamento de pessoal e monitoramento da área.

$\mathrm{Na}$ coleta e transporte externo para aterro sanitário, foram especificados os resíduos por grupo, a frequência, horário e tipo de veículo transportador e indicada a empresa responsável pela coleta externa, fornecendo nome, endereço, telefone/fax e os dados do responsável técnico.

\section{RESULTADOS E DISCUSSÃO}

A implantação de um serviço com qualidade envolve processo técnico administrativo destinado à tomada de decisão. Este posicionamento decisivo consiste no processo avaliativo que significa expor um valor assumido a partir do julgamento realizado com base em critérios previamente definidos (ABREU et al., 2007). Ao reavaliar, partindo da etapa 2 do plano, identificaram-se situações específicas problemáticas em relação aos resíduos gerados e utilizaramse instrumentos e referências para emitir um juízo de valor inerente ao processo. Nesta etapa 2, a reavaliação foi considerada de primordial importância, pois forneceu dados como dispostos na Tabela 1 que mostram o quantitativo dos resíduos sólidos úmidos e secos, conforme considerados por Kinasz (2007), produzidos mensalmente no RU.

O motivo pelo qual se observou queda na produção de resíduos secos nos fins de semana foi que, além da diminuição da produção de refeições, o que gerou a diminuição de frascos, embalagens e caixas de alimentos, não houve recebimento de mercadorias nesse período. Também não houve utilização de copos descartáveis, com a introdução dos copos de vidro nos finais de semana, havendo também o decréscimo do número de funcionários e de comensais. Com base nos 
dados apresentados, chegou-se ao cálculo do per capita médio de resíduos sólidos produzidos pelos comensais do RU, durante a semana e nos finais de semana.

Tabela 1 - Quantidade (em Kg) de resíduos úmidos e secos, na semana(segunda a sexta) e no fim de semana (sábado e domingo), produzidos na UAN do RU no período em 31 dias.

\begin{tabular}{|l|c|c|c|c|c|c|}
\hline DIAS & Úmido (kg) & $\begin{array}{c}\text { Média } \\
\text { diária (kg) }\end{array}$ & $\%$ & Seco (kg) & $\begin{array}{c}\text { Média } \\
\text { diária (kg) }\end{array}$ & $\%$ \\
\hline $\begin{array}{l}\text { SEMANA (21 } \\
\text { dias úteis) }\end{array}$ & $8.478,8$ & 402,72 & 84,79 & $1.093,2 \mathrm{Kg}$ & 53,97 & 95,74 \\
\hline $\begin{array}{l}\text { FIM DE } \\
\text { SEMANA (10 } \\
\text { dias - 5 fins de } \\
\text { semana) }\end{array}$ & $1.517,7$ & 151,77 & 15,21 & $49,6 \mathrm{Kg}$ & 4,96 & 4,26 \\
\hline $\begin{array}{l}\text { MÊS } \\
(31 \text { dias) }\end{array}$ & $\mathbf{9 . 9 9 6 , 5}$ & $\mathbf{3 2 1 , 7 7}$ & $\mathbf{1 0 0}$ & $\mathbf{1 . 1 4 2 , 8}$ & $\mathbf{3 7 , 5 6}$ & $\mathbf{1 0 0}$ \\
\hline
\end{tabular}

O mês analisado apresentou 4 semanas, totalizando 21 dias úteis e 10 dias de fins de semana. Considerando a produção semanal de aproximadamente 9.593,6 kg/comensal/dia da semana de resíduos sólidos, e sabendo que durante esses 21 dias passaram 47.467 comensais na linha de distribuição, tem-se um per capita médio de resíduo sólido de $0,2 \mathrm{~kg} /$ comensal/dia para resíduos sólidos em geral. Analisando que foram produzidos $8.478,8 \mathrm{~kg}$ de lixo úmido e $1.093,2 \mathrm{~kg}$ de seco, observaram-se os per capitas diários de $0,2 \mathrm{~kg} /$ comensal/dia da semana e 0,02 $\mathrm{kg} /$ comensal/dia de final de semana, respectivamente. Os resultados para a caracterização segundo a natureza foram apresentados de acordo com classificação de Kinacz (2007) (Tabela 2).

Analisando os resultados obtidos com a pesquisa realizada sobre a educação ambiental dos funcionários, gestores, estagiários e supervisores, pode-se perceber que, dos funcionários entrevistados, a maioria correspondeu ao sexo masculino (94\%), a faixa etária entre 22 e 27 anos (25\%) e 32 a 37 anos (25\%), com 1 a 4 anos de tempo de serviço. A maioria cursou ensino médio completo (44\%), consolidando perfil masculino: pouco tempo de trabalho, idade mediana e baixo grau de instrução. Participaram 32 voluntários dos 48 funcionários do Restaurante Universitário.

Tabela 2 - Caracterização segundo a natureza baseada na classificação de Kinacz (2007)

\begin{tabular}{|l|r|r|r|}
\hline RESÍDUOS & SEMANA/ Kg & FIM DE SEMANA/ kg & TOTAL/kg \\
\hline Papel/papelão & 21,60 & 3,13 & $\mathbf{2 4 , 7 3}$ \\
\hline Vidros & 11,88 & 1,81 & $\mathbf{1 3 , 6 9}$ \\
\hline Latas & 272,46 & 43,59 & $\mathbf{3 1 6 , 0 5}$ \\
\hline $\begin{array}{l}\text { Resíduos e aparas/ } \\
\text { preparo }\end{array}$ & $5.276,07$ & $1.099,50$ & $\mathbf{6 . 3 7 5 , 5 7}$ \\
\hline Restos e sobras & $3.181,13$ & 418,20 & $\mathbf{3 . 5 9 9 , 3 3}$ \\
\hline Outros componentes & 880.05 & 132,01 & $\mathbf{1 . 0 1 2 , 0 6}$ \\
\hline
\end{tabular}


Quanto à questão maiores dificuldades para minimizar os problemas do lixo, os funcionários pesquisados consideraram os fatores representados na Figura 1. Na Pesquisa realizada com gestor do RU, observou-se que a direção do restaurante tem conhecimento da importância do Gerenciamento dos Resíduos Sólidos e reconheceu a necessidade de trabalhar a sensibilização da importância de conservação ambiental. Os três fatores de desperdício predominantes em Unidades de Alimentação são: correção; sobras da produção; rejeitos (ABREU et al., 2007). Os principais pontos de desperdícios identificados foram em três setores distintos: a produção (cozinha), a devolução (copa de bandejas e pratos) e o almoxarifado com sobras descartadas do processo produtivo, sendo sobras inviáveis de reuso ou com grau de amadurecimento elevado de alimentos, entre outros (Figura 2).

O fator de correção do RU para perdas dos gêneros correspondeu, em média, a 32,3\%. Quanto às sobras da produção, os restos dos alimentos e avaliação subjetiva da clientela, calcularam-se os valores diários e médios encontrados durante a coleta de cinco dias de cardápio e estão descritos na Tabela 3:

Por último, foram analisados os cardápios do período da coleta e foram verificadas as preparações planejadas para o período e o que foi executado pelo almoxarifado. Com a realização da análise dos dados coletados, identificaram-se as razões para desperdício de estoque na UAN evidenciados no Quadro 1.

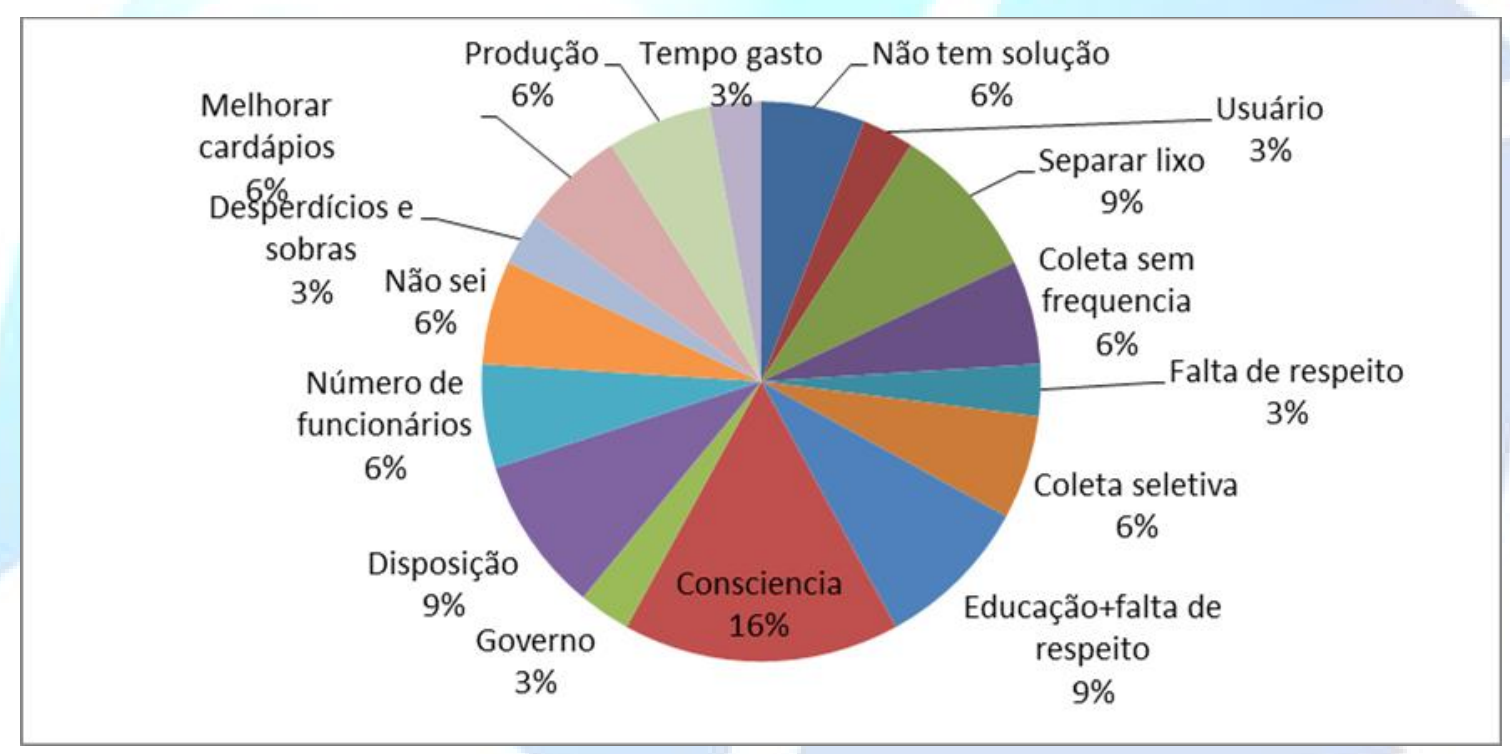

Figura 1. Maiores dificuldades enfrentadas para minimizar o problema do lixo 


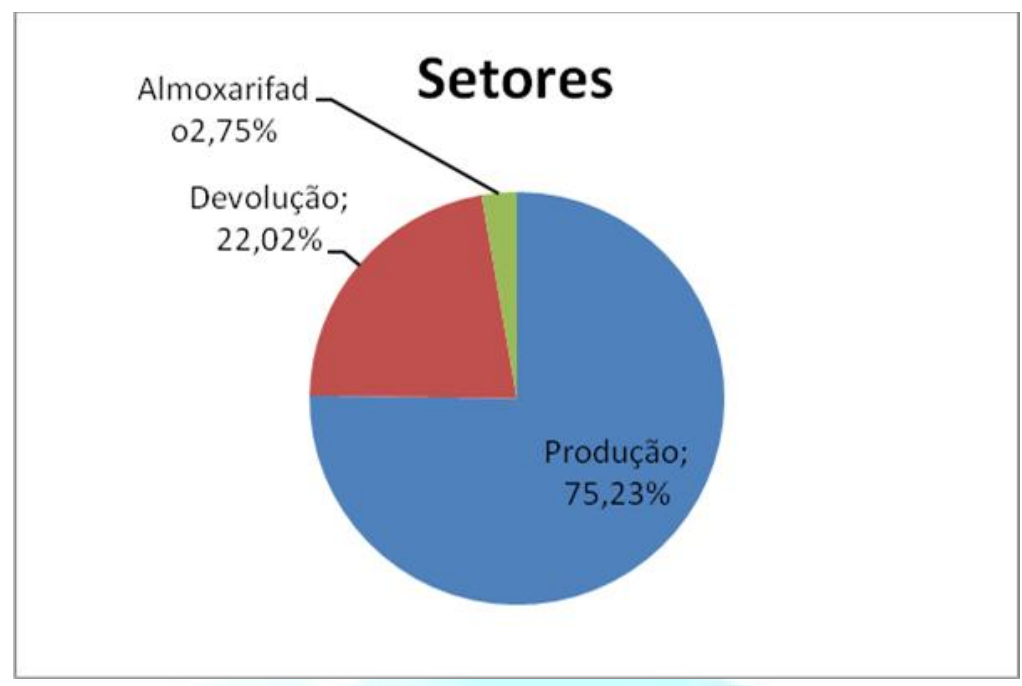

Figura 2. Os principais setores de desperdícios

Tabela 3 - Refeições rejeitadas

\begin{tabular}{|l|c|c|c|c|c|c|}
\hline Referências & Dia 1 & Dia 2 & Dia 3 & Dia 4 & Dia 5 & Média/dia \\
\hline $\mathrm{N}^{\mathbf{o}}$ de pessoas & 1227 & 1417 & 1375 & 1298 & 1121 & 1288 \\
\hline Restos (kg) & 151 & 178 & 112 & 119 & 134 & 139 \\
\hline $\begin{array}{l}\text { N Refeições } \\
\text { rejeitadas }\end{array}$ & 178 & 232 & 126 & 158 & 161 & 171 \\
\hline Classificação rejeito & $14,5 \%$ & $16,3 \%$ & $9,2 \%$ & $12,2 \%$ & $14,4 \%$ & $13,32 \%$ \\
\hline Avaliação subjetiva & Bom & Bom & Bom & Bom & Bom & Bom \\
\hline Custo refeição & 3,41 & 3,36 & 3,49 & 3,28 & 4,46 & 3,60 \\
\hline $\begin{array}{l}\text { Valor } \\
\text { desperdiçado/dia }\end{array}$ & 608,00 & 779,52 & 439,74 & 518,24 & 718,06 & 612,71 \\
\hline $\begin{array}{l}\text { Valor médio } \\
\text { desperdiçado/ mês }\end{array}$ & $18.381,36$ & & & & \\
\hline
\end{tabular}


Quadro 1 - Identificação das razões para desperdício de estoque da UAN do RU.

\begin{tabular}{|c|c|c|}
\hline \multicolumn{2}{|c|}{ Ações que levam ao desperdício } & Conseqüiências \\
\hline \multirow{6}{*}{$\begin{array}{l}\text { Planejamento } \\
\text { Inadequado }\end{array}$} & \multirow[t]{3}{*}{ Per capitas inadequados } & $\begin{array}{l}\text { Superprodução por liberação de matéria prima } \\
\text { calculada de última hora }\end{array}$ \\
\hline & & $\begin{array}{l}\text { Substituições de alimentos não planejados } \\
\text { para atender as necessidades imediatas }\end{array}$ \\
\hline & & Superprodução de refeições \\
\hline & $\begin{array}{l}\text { Organização inadequada } \\
\text { do cardápio }\end{array}$ & $\begin{array}{l}\text { Utilização excessiva de alguns itens } \\
\text { em detrimento de outros }\end{array}$ \\
\hline & $\begin{array}{l}\text { Ausência de margem de } \\
\text { segurança }\end{array}$ & Alteração do per capita \\
\hline & $\begin{array}{l}\text { Ausência de planejamento } \\
\text { de frutas para sucos e } \\
\text { sobremesas }\end{array}$ & Pedido de compras sem definição precisa \\
\hline Pedido & Fora do prazo & $\begin{array}{l}\text { Não foi identificado pedido de compras fora do } \\
\text { prazo }\end{array}$ \\
\hline Recebimento & Fora do prazo & $\begin{array}{l}\text { Não foi identificado pedido de compras fora do } \\
\text { prazo }\end{array}$ \\
\hline Armazenamento & $\begin{array}{l}\text { Áreas de armazenamento } \\
\text { com capacidade pequena } \\
\text { em comparação com a } \\
\text { produção }\end{array}$ & Conservação inadequada dos alimentos \\
\hline
\end{tabular}

$\mathrm{Na}$ fase 3, todas as etapas propostas foram descritas no plano de gerenciamento e definidas as metas de educação ambiental, de redução de geração, especificando classificação e quantidade dos resíduos gerados, com o nome da empresa geradora e das conveniadas para reaproveitamento, endereços, telefones/fax e dados do responsável técnico, assim como os procedimentos de manejo utilizados na segregação dos resíduos.

Torna-se necessário satisfazer o cliente tanto por aspectos tangíveis como intangíveis de qualidade. Os primeiros, qualidade, estão incorporados às características físicas dos produtos e se manifestam por meio do cardápio, apresentação dos alimentos, layout do restaurante e assim sucessivamente. Em contrapartida, as características intangíveis de qualidade estão relacionadas às expectativas, percepções, desejos conscientes e inconscientes do cliente (ABREU et al., 2007).

Durante muito tempo, acreditou-se que oferecer produtos e serviços de qualidade encareceria o processo produtivo. Este pensamento impediu que a produção atingisse todo seu potencial, pois a redução de custos, por diversas vezes, atrelava-se ao conceito do rebaixamento de qualidade, fosse ela vinculada à qualidade dos gêneros alimentícios ou da mão de obra, ou ainda ambos os casos.

A qualidade gera uma série de custos, entre eles aqueles de prevenção, que são todos os gastos feitos para evitar que se cometam erros e fazer com que o empregado sempre realize bem seu trabalho. A prevenção permite o desenvolvimento e implantação de um sistema de análise e apresentação de dados, conhecimento e aplicabilidade de fluxograma de processos, bem como um plano de controle de qualidade das atividades (TEIXEIRA, 1997), o que reforça a importância do diagnóstico operacional e produtivo para a execução do plano de gerenciamento.

$\mathrm{O}$ reconhecimento das operações produtivas, associadas à aplicabilidade e a implantação de um plano de gerenciamento integrado de resíduos, permitem a promoção de ajustes amplos nas instituições, nas quais vários atores certamente devem contribuir para que metas comuns sejam 
alcançadas. Isto se constitui em passo importante para entendimentos reais de modificação cultural, quando conceitos de segurança ambiental global e de desenvolvimento são centrais para o estabelecimento de técnicas de manejo ambiental, de combate ao desperdício e à poluição (RIBEIRO, 2001).

O novo cenário ambiental em construção busca um gradativo abandono do modelo linear de produção vigente, no qual a capacidade de exploração das fontes de materiais e energia, com aumento do consumo de bens, explora ao máximo a capacidade de saturação do ambiente. Este aspecto demonstra a irresponsabilidade com que nossa espécie tem tratado a questão dos recursos naturais, ocasionando exploração das matérias primas, na maioria das vezes, além da capacidade de regeneração destas. Assim, em época de aumento da consciência ambiental, urge não somente o crescente conhecimento das implicações sobre o meio ambiente, mas ainda a responsabilidade e cuidado com os subprodutos dos sistemas produtivos, pois sua produção inconsequente resulta em aumento de volume de resíduos a serem dispostos na natureza. A perspectiva da sustentabilidade deve ser incorporada ao gerenciamento desses resíduos gerados pela sociedade como um todo (DONAIRE, 1999; KINACZ, 2007).

Demandas de responsabilidade ambiental passam por associações produtivas e também pela sociedade como um todo. Assim sendo, as unidades produtoras de refeições não devem nem podem se eximir desta realidade. De modo abrangente, poder-se-ia afirmar que o oferecimento de uma alimentação ambientalmente equilibrada constitui um instrumento sincrônico de preparações nutricionalmente adequadas, com custos equacionados com a realidade da empresa e, ainda assim, com produção consciente e respeitosa em relação ao meio ambiente.

\section{CONCLUSÕES}

A finalidade deste trabalho é demonstrar que o plano de Gerenciamento Integrado de Resíduos Sólidos em UANs permite conhecer etapas de operações de manipulação de alimentos, com o objetivo final de promover um padrão de qualidade, de identidade dos insumos e dos produtos gerados, para viabilizar uma operacionalização dos resíduos de forma ambientalmente correta.

O modelo de referência proposto por Menezes e Menezes (1999) forneceu diretrizes esquemáticas para a elaboração deste Plano em restaurantes, sendo sua proposição bastante similar ao Manual de Boas Práticas de Fabricação, tornou-se extremamente exequível e oportuno uma vez que sua dinâmica organizacional é perfeitamente aplicada em UANs. Este plano auxilia na eficácia do processo, atuando como ferramenta operacional, que promove melhorias na gestão com reflexos positivos na área econômica e ambiental.

No restaurante institucional, o diagnóstico obtido nas etapas de construção do plano foi tão relevante que foi criada permanentemente uma Coordenadoria de Gestão Ambiental para trabalhar a gestão e educação ambiental no local, com metas semestrais de sensibilização de usuários, estagiários e funcionários do restaurante, e bienais para reaplicação do plano de Gerenciamento de Resíduos Sólidos. Parcerias e encaminhamentos para início da coleta seletiva também foram firmados, para o alcance das metas.

Conclui-se que o Gerenciamento de Resíduos Sólidos não depende apenas de um tratamento técnico apropriado, mas também de tratamento cultural adequado: mudanças de hábitos e valores são essenciais numa sociedade em que se predominam hábitos de desperdício e de descaso em relação ao público, ao cidadão e ao meio ambiente. 


\section{AGRADECIMENTOS}

A Deus, por sua fidelidade, aos professores Karen Maria da Costa Mattos, Nominando Andrade de Oliveira, Mario Orestes Aguirre González e Carlos Henrique Catunda Pinto pelo acompanhamento. A minha família querida e a todos que direta ou indiretamente contribuíram para a realização desta pesquisa.

\section{REFERÊNCIAS}

ABREU, E.; SPINELLI, M.G.; PINTO. A.M. Gestão de unidades de alimentação e nutrição: um modo de fazer. 2. ed. [rev. e ampl.]. São Paulo: Editora Metha, 2007. 318p.

ASSOCIAÇÃO BRASILEIRA DE NORMAS TÉCNICAS. NBR ISO 14004: Sistemas de gestão ambiental: diretrizes gerais sobre princípios, sistemas e técnicas de apoio. Rio de Janeiro, 1996a. BRASIL. Lei No 12.305 de 02 de Agosto de 2010. Institui a Política Nacional de Resíduos Sólidos; altera a Lei $\mathrm{n}^{\circ}$ 9.605, de 12 de fevereiro de 1998; e dá outras providências. Disponível em: < http:// www.planalto.gov.br/ccivil_03/_ato2007-2010/lei/11230> Acesso: julho/2010.

. Resolução RDC no 216 de 15 de setembro de 2004. Dispõe sobre o regulamento Técnico de Boas Práticas para o Serviço de Boas Práticas de Alimentação. Diário Oficial da União, Brasília, DF, de 16 de setembro de 2004. Disponível em:

http://elegis.anvisa.gov.br/leisref/public/showAct.php?id=12546> Acesso em: 04 de set, 2009.

DONAIRE, D. Gestão ambiental na empresa. 2 ed. São Paulo: Atlas, 1999. 176p.

KINASZ, T.R. Reflexão Teórica sobre Gerenciamento de Resíduos Sólidos em Unidade de Alimentação e Nutrição. Revista Nutrição em Pauta, São Paulo, v. 15, p.56-60, 2007.

MENEZES, R. A.; MENEZES, M. A. Considerações sobre o gerenciamento integrado de resíduos sólidos (GIRS). 53 ${ }^{\mathrm{a}}$ ed. São Paulo. p.12-17, 1999.

MONTEIRO, J.H.P., FIGUEIREDO, J.H.; MAGALHÃES, A.F., MELO, M.A., BRITO, J.C., ALMEIDA, T.P., MANSUR, G. L. Manual de gerenciamento integrado de resíduos sólidos. Rio de Janeiro: IBAM, 2001. $200 \mathrm{p}$.

Sólidos. Rio de Janeiro: IBAM, 2001. 200 p.

RIBEIRO, L.A. Avaliação de barreiras para implementação de um sistema de gestão ambiental na ufrgs. In: XXV ENEGEP. Porto Alegre, RS. 29 out. a 01 nov.2005.

TEIXEIRA, S.M.F.G. Funcionamento das unidades de alimentação e nutrição. In:

Administração aplicada às Unidades de Alimentação e Nutrição. São Paulo: Atheneu, p. 165-219. 1997. 